\title{
DOSSIÊ - A QUADRATURA DO CÍRCULO: TRADUÇÃO DA (E PARA A) POESIA CHINESA
}

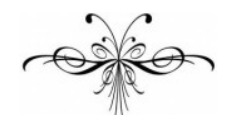

\author{
RAQUEL ABI-SÂMARA
}

$\boldsymbol{\zeta} \boldsymbol{\zeta}$ Tá se disse que traduzir poesia chinesa para um idioma ocidental seria algo tão impossível como a quadratura do círculo"1 (Campos, 1995: 235). Assim escreve Haroldo de Campos, um dos mais brilhantes intelectuais brasileiros, e, sem dúvida alguma, um dos mais criativos tradutores do século XX, ao lado de Ezra Pound e de Augusto de Campos. "É da essência mesma da tradução de poesia", prossegue, “o estatuto da impossibilidade. Para quem aborda a arte de traduzir poesia sob a categoria da criação, essa superlativação das dificuldades que lhe são intrínsecas só pode acrescer-lhe, na medida proporcional, o fascínio" (idem).

Não é aleatório o início deste dossiê com as palavras de Haroldo. A clareira aberta por esse poeta-inventor, ao traduzir a poesia chinesa para o português, jamais poderá ser ignorada pelos tradutores que buscam, por caminhos criativos, lidar com a impossibilidade da transformação do círculo em quadrado, dos caracteres chineses em escrita fonológica, da poesia chinesa em idiomas indo-europeus. Se a geometria tradicional euclidiana esbarra nessa impossibilidade de trans-posição do círculo ao quadrado e do quadrado ao círculo, a arte da tradução criativa de Haroldo de Campos oferece uma espécie de caminho topológico para a quadratura do círculo. Se imaginarmos que um círculo traçado sobre uma folha/superfície elástica pode ser transformado num quadrado, desde que essa superfície aceite golpes precisos de deformações, e que ainda assim o círculo consegue preservar propriedades qualitativas que lhe são invariáveis, é essa a arte da tradução de Haroldo. Ou pensemos ainda numa outra imagem, cara aos estudos da geometria não-euclidiana: a fita de Moebius, em que um ponto qualquer nela traçado consegue estar simultaneamente dentro e fora dessa estru-

\footnotetext{
${ }^{1}$ Haroldo de Campos refere-se à comparação feita por Siegfried Behrsing, citada por W. McNaughton, Ezra Pound et la Littérature Chinoise. In: Revista de Cultura (RC). N. 25 (II série). Instituto Cultural de Macau: 1995. A publicação na RC consiste de duas partes extraídas dos seguintes livros de Haroldo: CAMPOS, Haroldo de. A arte no horizonte do provável. São Paulo, Perspectiva, 1969, p. 121-7; CAMPOS, Haroldo de. A operação do texto. São Paulo: Perspectiva, 1976, p. 141-2, 146.
} 
tura, por assim dizer, matemática. Parece comparável a poemas traduzidos por Haroldo, que por vezes chega a "interpolar estrategicamente pictogramas do original no texto em português" ${ }^{2}$ (Campos, 2009:22), numa espécie de tradução ao avesso, com espelhamentos e esquemas paralelísticos, em termos gráficos, sonoros, semióticos e semânticos, entre dois sistemas de escrita nem um pouco familiares entre si.

É nesse caminho de poeta-inventor, em busca constante da 'quadradura do círculo’, com muito conhecimento da tradição e da matéria poética, tanto em língua portuguesa quanto em língua chinesa, que trilha Ricardo Portugal, ao apresentar sua antologia de poemas clássicos chineses da Dinastia Tang (618907), traduzidos em parceria com Tan Xiao. Como se verá na mostra de poemas apresentados neste dossiê, há não somente um olhar atento para as tradições poéticas nas línguas de saída e de chegada, como também uma escuta apurada da poesia dessas tradições. Os recursos da poesia clássica de língua portuguesa tais como as inversões sintáticas, o metro decassilábico etc certamente contribuem para abrigar o poema clássico chinês na língua portuguesa, o que se consegue com bastante flexibilidade e, sobretudo, soluções criativas. A forma, seja visual ou acústica, é tratada nesses poemas traduzidos com merecida atenção: "não é possível realizar uma tradução poética que recupere minimamente o ori-ginal apenas com a reprodução do conteúdo, sem consciência de linguagem em relação à forma”, adverte Ricardo Portugal.

Se a metáfora da quadratura do círculo é válida também para o caminho inverso, da tradução da poesia de um idioma ocidental para o idioma chinês, vamos buscar saber por meio de análises e reflexões teóricas de escritores, poetas e estudiosos chineses. É essa a proposta de Júlio Jatobá, no artigo "Poesia e (in)traduzibilidade na língua chinesa”, onde vai apresentar brevemente quatro autores chineses significativos para a história da tradução da poesia sinoocidental, para além de Yan Fu, cuja proposta de tradução poética, conforme discute Júlio, tem como base a tríplice questão "fidelidade/fluidez/elegância", que ficou consagrada nos estudos da tradução na China como xin da ya ( $x i n=$ fidelidade; $d a=$ fluidez; $y a=$ elegância). A língua chinesa, matéria prima para a escrita da poesia, não poderia também deixar de ser aqui analisada. Afinal, o que é a língua (ou as línguas) chinesa(s)? Pode-se falar de uma língua única chinesa ou seria preferível se pensar no chinês como uma família de línguas? Essa reflexão faz Júlio Jatobá em seu artigo.

E o que dizer da tradução da poesia contemporânea? A língua chinesa, como afirma François Cheng, será "metamorfoseada, (...) como o mostrará, um milhar de anos mais tarde, cerca de 1920, a morte do wen yan 'língua escrita antiga' e a sua substituição pelo bai hua, 'língua moderna', que conduzirá a poesia a outras aventuras” (Cheng, 1995:15). Se a poesia tradicional chinesa de formas rigorosas, como por exemplo o lüshi, traz em sua bagagem de dificuldades a serem transportadas para outro idioma questões como o complexo contraponto tonal, o paralelismo entre dísticos de versos, a elipse dos pronomes pessoais, a oposição entre palavras plenas e palavras vazias etc, o que di-zer da poesia con-

\footnotetext{
${ }^{2}$ CAMPOS, Haroldo de. Escrito sobre jade. Poesia clássica chinesa reimaginada por Haroldo de Campos. São Paulo: Ateliê Editorial, 2009. Conferir o poema de Li Po, "Bebendo solitário sob a lua” ("Entre flores”), traduzido por Haroldo com a utilização da estratégia de interpolação mencionada. O poema encontra-se na página 71 desse livro.
} 
temporânea? Em entrevista para este dossiê, o poeta Yao Feng (pseudônimo de Yao Jingming), um dos mais prestigiados tradutores de poesia de língua portuguesa para o chinês, falará um pouco de sua vasta experiência como poetatradutor de poesia e como acadêmico-especialista em reflexões sobre tradução poética. Sua experiência inclui reflexões sobre tradução de poesia clássica chinesa para o português, tradução de poetas modernos e contemporâneos de língua portuguesa para o chinês, e também a tradução, ainda que em menor escala, de poemas chineses contemporâneos para a língua portuguesa. Ao final da entrevista, Yao nos brinda um poema de um de seus poetas preferidos, Carlos Drummond de Andrade. Yao reimagina Carlos: “o mundo é grande” em chinês.

E também do time dos mais laureados tradutores de poemas ocidentais para o chinês, temos, de Laurence Wong (pseudônimo de Huang Guobin), o artigo "Traduzindo a imagística de Shakespeare para o público chinês - com referência a Hamlet e as suas versões em chinês e em línguas europeias”, traduzido do inglês por Gustavo Althoff. Fala-se muito da exuberância de imagens e metáforas na poesia chinesa, possibilitadas por caracteristicas próprias dos caracteres chineses. Laurence faz o caminho contrário, parte de textos teatrais de Shakespeare que traduziu para o chinês e constata que os diálogos em Hamlet, em sua maioria, são compostos por uma sequência de metáforas, de modo possivelmente tão amplo e rico como na poesia tradicional chinesa. Laurence discute a questão das imagens e da metáfora em Shakespeare, destacando categorias de imagens que contribuem, como ferramentas indispensáveis, para a prática reflexiva da tradução de poesia. (Assinala também características rítmicas da poesia chinesa contemporânea, marcadas por pausas, por exemplo, e não mais por tons e contrapontos tonais, como nos poemas clássicos). Outro aspecto relevante destacado por Laurence nesse artigo é o fato de que os versos de Hamlet, ao serem traduzidos para o chinês, devem ser pensados como versos a serem lidos em voz alta, a serem representados nos palcos, em cenas dramáticas, e não lidos silenciosa e individualmente, o que determina, e muito, o resultado de sua dinâmica. Vale destacar aqui que Huang Guobin é considerado na China um dos melhores tradutores de Dante Alighieri. Traduziu a Divina Comédia para o chinês, admiravelmente toda em terza rima, como no poema original de Dante.

$\mathrm{O}$ artigo "Entre idiomas ocidentais e o chinês: o império dos significados na tradução de poesia, a exemplo de Mao Dun”, discute uma tendência na tradução da poesia ocidental para o chinês (e vice-versa), desde o início dessas traduções na China, que ocorreram na década de 1920, logo após o Movimento 4 de Maio (1919). Essa tendência consiste no privilégio do sentido ou dos significados sobre a forma e, principalmente, sobre a unidade forma-sentido do poema. Mao Dun foi um escritor e intelectual de grande influência para a revolução literária na China. Apesar de defender a tradução parcial de um poema, a tradução por sentido, ou, como bem define Antoine Berman, em sua perspectiva da filosofia da tradução, a tradução platônica, Mao Dun tem uma visão ampla e mesmo "polissistêmica" da tradução de poesia (e de literatura, de modo geral). Dun tem plena consciência da influência e do poder de transformação que uma literatura pode ter sobre outra, ou que uma cultura pode ter sobre outra, por meio da tradução da literatura.

Em arremedo a retas paralelas que, ficcionalmente ou não, se vão encontrar no infinito, os artigos desse dossiê apresentam um paralelismo em suas 
reflexões, e coincidem em um ponto comum: a necessidade infinita de se continuar a pensar a 'quadratura do círculo' em todos os aspectos possíveis, presentes no ofício intuitivo e consciente do verso, e do anverso, como numa fita de Moebius, em que dentro e fora não se separam, assim como sentido e forma, que não se devem separar, para que a tradução platônica não seja nesse contexto um imperativo categórico.

Raquel Abi-Sâmara

raquelmag@umac.mo

Profa. Dra., Universidade de Macau 